\title{
Investigations on the impact of the hole surface integrity on the fatigue life of a 2024-T351 aluminum alloy drilled part
}

\author{
Alexandra Lacombe ${ }^{1}$ (1) $\quad$ Yann Landon $^{1} \quad$ Manuel Paredes $^{1}$ \\ Damien Texier $^{1}$ () Clément Chirol ${ }^{2}$ Audrey Benaben ${ }^{2}$
}

${ }^{1}$ Institut Clément Ader UMR CNRS 5312, Université de Toulouse, UPS, INSA, ISAE-SUPAERO, MINES-ALBI, CNRS, Toulouse, France

${ }^{2}$ D41, Airbus France, Toulouse, France

Correspondence

Alexandra Lacombe, Institut Clément Ader UMR CNRS 5312, Université de Toulouse, UPS, INSA, ISAE-SUPAERO, MINES-ALBI, CNRS, 3 rue Caroline Aigle, Toulouse, France.

Email: alexandra.lacombe1@univ-tlse3.fr

\begin{abstract}
The influence of the hole surface integrity on the fatigue life of 2024-T351 aluminum drilled parts was investigated. Fatigue tests were conducted on open-hole specimens, and a large campaign was carried out to characterize the hole surface integrity (roughness measurements, hardness measurements, metallographic observations, and residual stress analysis). An innovative technique, the Hole Opening Comparative Technique, was set up in order to analyze the residual stress state of the parts. In this study, strain hardening of the hole subsurface seems to be the main factor influencing the fatigue behavior, associated with a residual stress state of the part.
\end{abstract}

\section{K E Y W O R D S}

aluminum alloy, fatigue strength, hardness, residual stress, surface roughness

\section{INTRODUCTION}

Parts of aircraft structures are mostly assembled using fasteners (rivets or screws) introduced into holes machined by drilling. Assembling an aircraft may require several hundred thousand to several million drilling operations depending on the aircraft size. ${ }^{1}$ These holes for fastening are critical areas where fatigue damage can be initiated because they are areas of high stress concentration. The drilling procedure used for the machining of the fastening holes can affect the fatigue life of the drilled part $^{2-4}$ since, according to the procedure, the hole surface is subjected to different thermo-mechanical loads that can induce differences in the hole surface integrity. ${ }^{5}$

Field and Kahles ${ }^{6}$ were the first to introduce the concept of surface integrity in a technical sense by defining it as the inherent or enhanced condition of a surface produced in machining or other surface generation operation. Since then, this definition has been completed by adding the notion of surface functional performance. Thus, according to Mondelin, ${ }^{7}$ the surface integrity can be considered as a set of characteristics allowing a surface to be qualified with regard to a given application. Regarding the fatigue performance of a surface, it is well known that the surface integrity includes the concepts of surface topography, residual stresses, and the metallurgical condition of the material subsurface (microstructure and microhardness).

Extending the fatigue life of aircraft is one of the aircraft industry's major concerns. This requires an understanding of the impact of the surface integrity on the fatigue strength. Thus, several works have been carried out in the past few decades to study the relationships between the machining process parameters, the resulting surface integrity, and the associated fatigue life for various materials and machining processes. The reviews by Novovic et al., ${ }^{8}$ M'Saoubi et al., ${ }^{9}$ and Pramanik et al. ${ }^{10}$ synthesize many of these works. The main conclusions concerning the individual contributions of the surface integrity parameters for commonly used materials (aluminum alloys, titanium alloys, steel, and nickel alloys) are the following. The lower the surface roughness, the longer the fatigue life $^{11}$ as the micro-notches of a machined surface induce stress concentration areas 
where a local plastic strain field can be generated when a stress is applied, thus defining a path for the crack. Compressive residual stresses improve the fatigue strength due to the crack closure effect, which slows crack propagation. ${ }^{12-14}$ In contrast, tensile stresses reduce the fatigue strength through the crack opening effect, which facilitates crack propagation. The fatigue life increases with the work hardening of the surface, which increases the surface yield strength. ${ }^{15,16}$ These surface integrity parameters have different impacts in the fatigue failure: some influence crack initiation and some influence crack propagation ${ }^{17}$ (Table 1).

However, a machining operation impacts all the surface integrity parameters mentioned above at the same time, and some parameters depend on one another, so it seems difficult to judge which parameter has a predominant influence on the others. Moreover, depending on the level range considered for a parameter, its influence on the fatigue strength can vary. For instance, according to Siebel and Gaier, ${ }^{18}$ a reduction in the fatigue endurance limit occurs only above a certain critical groove depth. In addition, the impact of the surface integrity parameters varies from one material to another. Koster ${ }^{19}$ showed that the endurance limit of steels was dependent on the surface roughness, whereas this was not the case for Ti 6-6-2 and Inconel 718.

Thus, the question of the relationship between the surface integrity and the fatigue strength seems very broad and complex, and the conclusions of the works cited in the reviews mentioned above cannot be generalized to all machining processes and to all materials. In some fields, there are gaps in our understanding of these correlations. This is the case for the hole surfaces obtained by drilling processes in aluminum alloys, which are the most widely used alloys in the aircraft industry. A clear understanding of the impact of these surfaces' integrity on the fatigue life of the drilled part is not yet available, although it is required by the aircraft industry to optimize the fatigue behavior of their assemblies.

The lack of studies on the integrity of drilled aluminum surfaces may be explained by the fact that the thinness of the layer of material affected by the machining

T A B LE 1 The influence of surface integrity characteristics on fatigue failure ${ }^{17}$

\begin{tabular}{|lll|}
\hline & $\begin{array}{l}\text { Crack } \\
\text { nucleation }\end{array}$ & $\begin{array}{l}\text { Crack } \\
\text { propagation }\end{array}$ \\
\hline Surface roughness & Accelerates & No effect \\
\hline Cold work & Retards & Accelerates \\
\hline $\begin{array}{c}\text { Residual compressive } \\
\text { stress }\end{array}$ & $\begin{array}{c}\text { Minor or no } \\
\text { effect }\end{array}$ & Retards \\
\hline
\end{tabular}

process makes the experimental characterization of the surface integrity difficult. A preliminary finite element study simulating the lateral cutting of a drilling process in a 2024-T351 aluminum part was lead in order to precise this depth of subsurface material affected. The finite element model developed for this study was a mechanical model equivalent to the one developed by Atlati $^{20}$ and was developed with the Abaqus/explicit software. The mechanical laws of material behavior and friction, and the simulation strategy used, were based on those employed by Atlati. $^{20}$ The study results showed that the depth of the subsurface material affected by plastic strain and residual stresses after machining was a few tens of microns (Figure 1). This depth is very small compared with the one usually studied in the edge area of hole for fasteners in the literature (a few millimeters). ${ }^{2,13,14}$

This paper investigates the impact of the hole surface integrity on the fatigue life of a 2024-T351 aluminum drilled part. This alloy was chosen because it is commonly used in the aircraft industry due to its low density and its high fatigue performance. As axial and orbital drilling processes can lead to different fatigue lives, ${ }^{21,22}$ these two processes were considered in the study in order to generate potential differences in hole surface integrity. Axial drilling is the most common process for the machining of a fastening hole in the aircraft industry and is usually named "conventional drilling." Orbital drilling is a more recent process, corresponding to helical milling (Figure 2), which has many advantages over the conventional process, such as avoiding burr formation and allowing better chip evacuation. ${ }^{23}$

To carry out the study, fatigue tests and surface integrity analysis (roughness measurements, hardness measurements, metallographic observations, and residual stresses analysis) were performed in order to identify the parameters that control the fatigue life.

\section{MATERIALS AND METHODS}

\subsection{Test specimens}

Fatigue specimens were machined from 2024-T351 aluminum plates. This aluminum alloy is an $\mathrm{Al}-\mathrm{Cu}-\mathrm{Mg}$ alloy which has been solution heat treated, control stretched, and naturally aged. The mechanical characteristics of the specimens are presented in Table 2.

Fatigue specimens were "open-hole" T-type elementary specimens (Figure 3) machined in such a way that their longitudinal axis was aligned with the rolling direction of the 2024-T351 plate. The specimen width was three times the nominal hole diameter $(D)$, and its length 

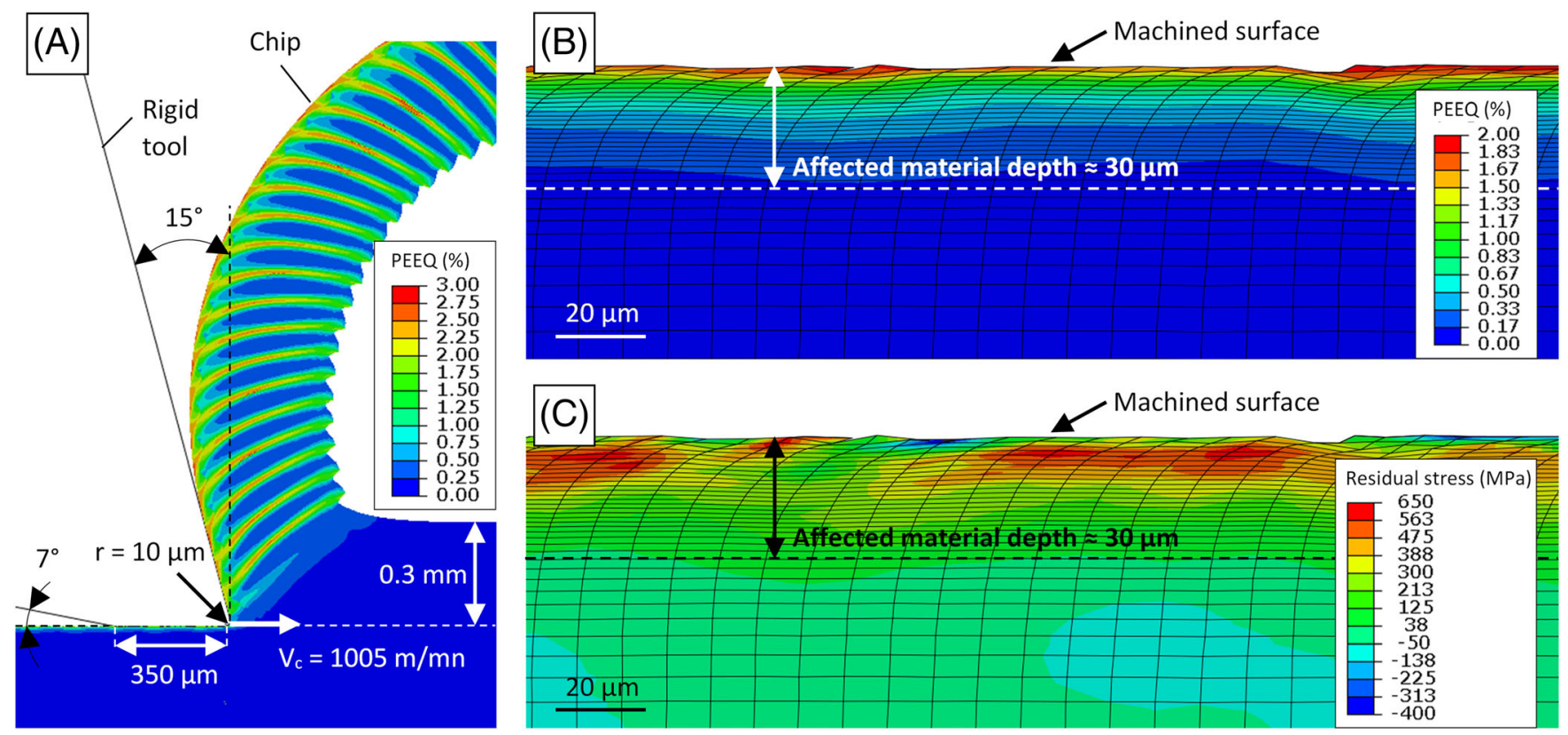

FI G URE 1 Results of the lateral cutting simulation: chip morphology (A), equivalent plastic strain of the subsurface (B) and residual stress of the subsurface in the tangential direction (C)

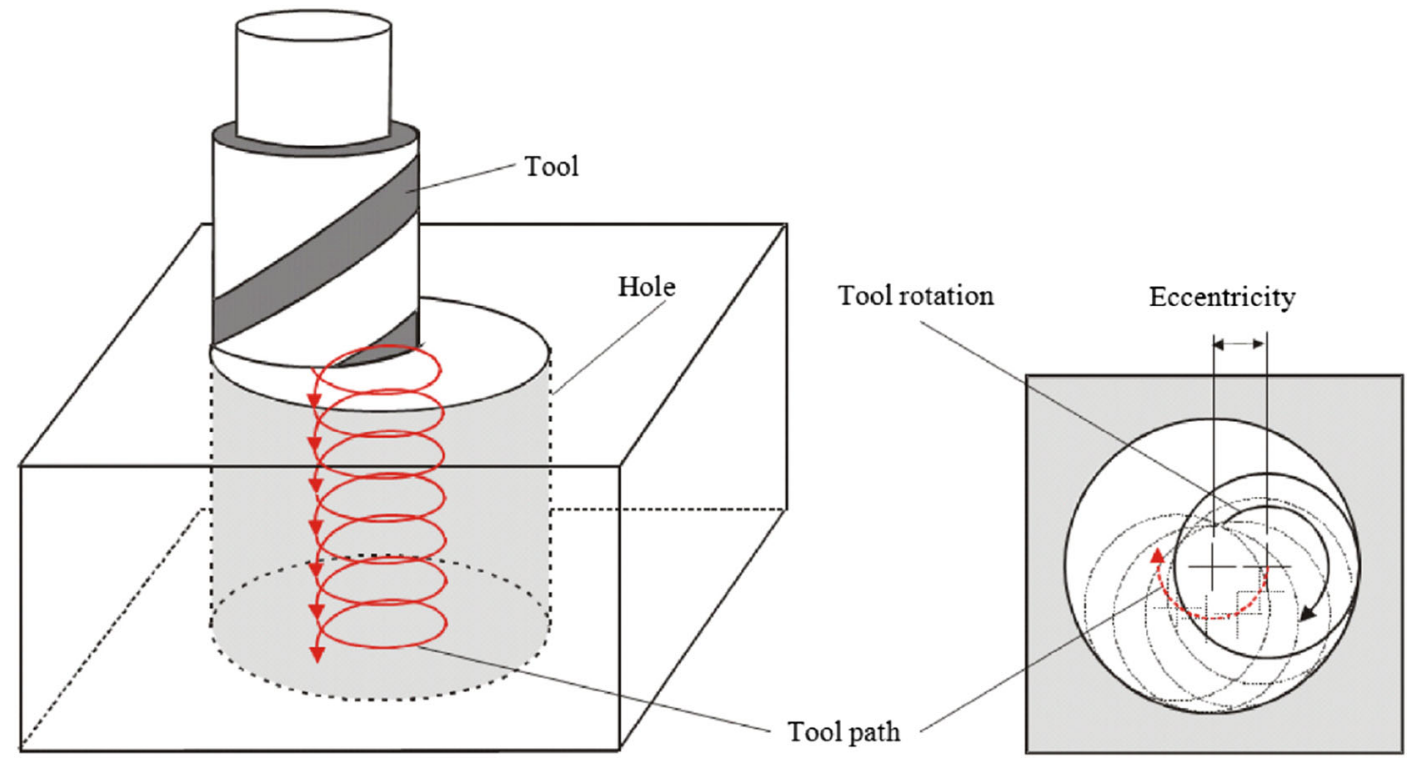

FI G U RE 2 Kinematics of the orbital drilling process ${ }^{22}$

TA B LE 2 Minimum mechanical properties for 2024-T351 aluminum plate (NF EN 485-2+A1, 2018)

\begin{tabular}{lll}
$\boldsymbol{R}_{\mathbf{p 0 . 2}}(\mathbf{M P a})$ & $\boldsymbol{R}_{\mathbf{m}}(\mathbf{M P a})$ & $\boldsymbol{A}(\boldsymbol{\%})$ \\
\hline 290 & 430 & 11 \\
\hline
\end{tabular}

was $200 \mathrm{~mm}$. The holes were obtained by a one-step drilling operation followed by a deburring operation.

To generate potential differences in hole surface integrity, axial and orbital drilling processes corresponding to industrial applications were used. As different tools and cutting parameters are used with these processes from one drilling diameter to another, two drilling diameters were considered in the study: 6.35 and $9.53 \mathrm{~mm}$.

The fatigue specimen thickness was chosen according to industrial applications. It was $6.35 \mathrm{~mm}$ for the specimens with $D=6.35$ and $10 \mathrm{~mm}$ for the specimens with $D=9.53 \mathrm{~mm}$.

According to Faurie et al., ${ }^{24}$ the stress concentration factor in the working section (gross section minus hole area) of the specimens was 3.5. The maximum stress in 


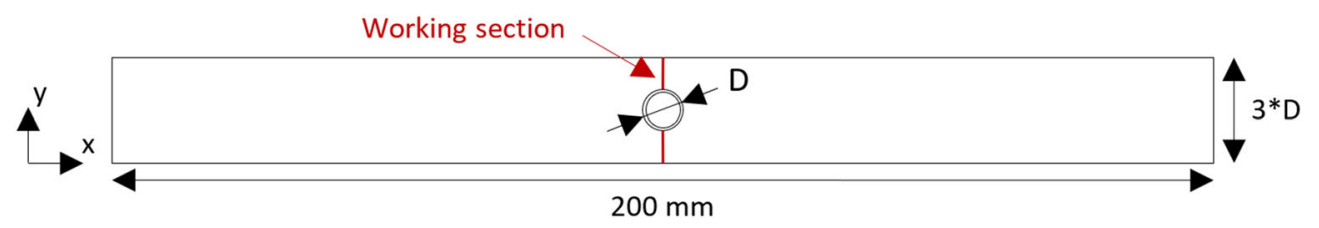

FIG URE 3 Fatigue specimen geometry

TABLE 3 Drilling parameters

\begin{tabular}{|c|c|c|c|c|}
\hline & \multicolumn{2}{|l|}{$D=6.35 \mathrm{~mm}$} & \multicolumn{2}{|l|}{$D=9.53 \mathrm{~mm}$} \\
\hline $\begin{array}{l}N_{\text {spindle }} \\
\quad(\mathrm{rpm})\end{array}$ & 9000 & 40,000 & 4000 & 40,000 \\
\hline$N_{\text {orb }}(\mathrm{rpm})$ & - & 1500 & - & 1500 \\
\hline$V_{\mathrm{c}}(\mathrm{m} / \mathrm{min})$ & 180 & 610 & 120 & 1005 \\
\hline$f_{\mathrm{a}}(\mathrm{mm} / \mathrm{rev})$ & 0.1 & 0.0015 & 0.1 & 0.0015 \\
\hline Tool & $\begin{array}{l}\text { Tungsten carbide helical } \\
\text { drill ( } 2 \text { tooth) }\end{array}$ & $\begin{array}{l}\text { Tungsten carbide end } \\
\text { mill ( } 4 \text { tooth) }\end{array}$ & $\begin{array}{l}\text { Step helical tungsten carbide } \\
\text { diamond coated drill ( } 2 \text { tooth) }\end{array}$ & $\begin{array}{l}\text { Tungsten carbide end } \\
\text { mill ( } 4 \text { tooth) }\end{array}$ \\
\hline
\end{tabular}

the hole edge area is obtained by multiplying the stress in the gross section by the stress concentration factor. The value of the stress concentration factor considered in this study ensured that the onset of cracking took place at the hole edge.

\subsection{Procedures}

\subsubsection{Drilling processes}

Drilling tests were carried out using a DMG DMU85eVo machining center. In order to conduct orbital drilling operations, a PRECISE France - ORBIBOT orbital spindle was fixed on the $Z$-axis of the machining center. For this drilling process, the machining was done in up-milling (tool rotation and orbital rotation in the same sense).

The cutting parameters, the tools, and the lubrication used for each drilling process and for each hole diameter corresponded to industrial applications. They are presented in Table 3.

\subsubsection{Fatigue tests}

Fatigue tests were performed using a Schenk servo hydraulic machine equipped with a $100-\mathrm{kN}$ load cell, at room temperature. The load was applied in the longitudinal direction of the specimen as a cyclic (sinusoidal) tensile-tensile load with a load ratio of 0.1 and a frequency of $20 \mathrm{~Hz}$. Fatigue tests were carried out for various stress levels in order to obtain $S$ - $N$ curves (Wöhler curves). The maximum stress level applied in the working section varied from 100 to $280 \mathrm{MPa}$.

\subsubsection{Roughness measurements}

Two-dimensional roughness parameters ( $\mathrm{Ra}, \mathrm{Rq}, \mathrm{Rz})$ were measured along the height of the hole with a profilometer. In accordance with [ISO 4288, 1996], these measurements were performed with a cut-off length of $0.8 \mathrm{~mm}$.

In order to complete the roughness results obtained from the analysis of linear profiles, an analysis of the surface roughness was also carried out. Three-dimensional roughness parameter measurements $(\mathrm{Sa}, \mathrm{Sq}, \mathrm{Sp}, \mathrm{Sv}, \mathrm{Sz}$, Sdq, Ssk, Sku) were made using an ALICONA Infinite Focus device, which is capable of performing noncontact optical surface topology measurements through the focus variation principle. A magnification of $10 \times$ and a vertical resolution of $200 \mathrm{~nm}$ were used for the measurements.

\subsubsection{Hardness measurements}

Vickers microhardness measurements were made on the hole surface of the fatigue specimens previously cut in the working section (Figure 4). The indentations were 
made with a load of $1 \mathrm{kgf}$ and an indentation time of $15 \mathrm{~s}$. Because of the cylindrical shape of the hole, a corrective factor was applied to the results as recommended by [ASTM E92-82].

In order to complete the microhardness results and to identify the material depth affected by a variation in hardness, nanoindentation tests were also conducted. The indentations were made at mid-thickness of the fatigue specimen in the $(x, y)$ plane. To do this, specimens were extracted from fatigue specimens and set in a resin in order to be polished. They were polished manually using emery papers with decreasing grit size (down to 4000 grit), then using diamond paste $(1 \mu \mathrm{m})$, and finished with OP-S suspension. The applied load and the size of the indentation matrix were determined on the basis of the results of the preliminary numerical study, which predicted an affected material depth of a few tens of microns (Figure 1). The indentation matrix was a matrix

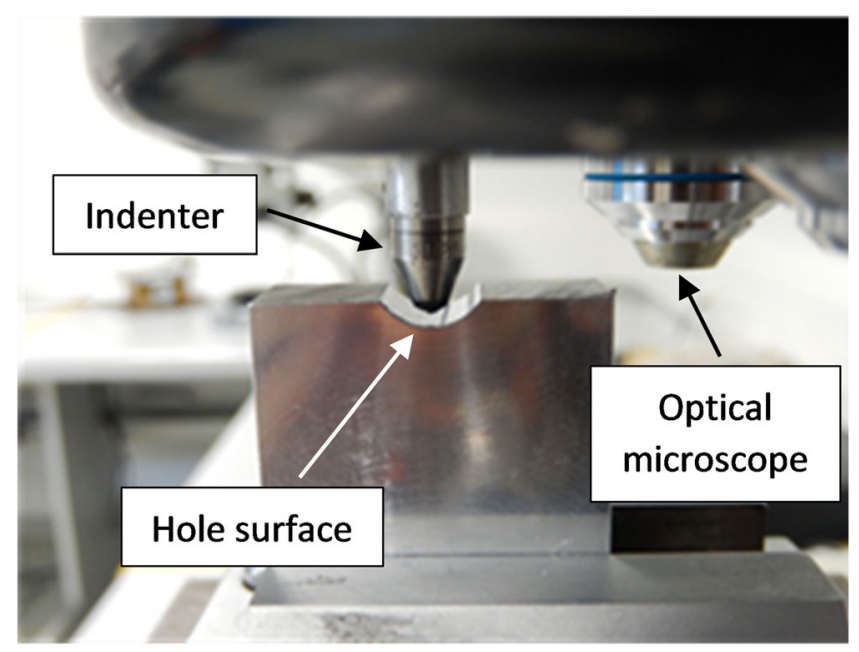

FI G URE 4 Vickers microhardness test set-up of $5 \times 20$ indents equally spaced $5 \mu \mathrm{m}$ apart, with the first column located around $5 \mu \mathrm{m}$ from the hole edge (Figure 5). The indentation tests were performed, with a diamond Berkovich indenter, as load-controlled tests with a maximum load of $5 \mathrm{mN}$. Load-displacement curves obtained were analyzed using the Oliver and Pharr method $^{25}$ to determine the nanohardness HIT.

\subsubsection{SEM-EBSD analysis}

Previous works had shown that the electron back-scatter diffraction (EBSD) technique could be used to localize and estimate plastic strain through the analysis of local changes in the crystal orientation. ${ }^{26,27}$ This technique was therefore used in the study to assess the strain hardening state of the hole subsurface. The grain reference orientation deviation (GROD), which represents the misorientation between a given pixel and the average orientation of the grain, was studied as a plasticity marker.

SEM-EBSD observations were carried out using a Feg Jeol JSM $7100 \mathrm{~F}$ scanning electron microscope (SEM) equipped with an Oxford Instruments Nordlys Nano detector (Centre de microcaractérisation Raimond Castaing, CNRS UMS 3623, Toulouse, France). They were performed on a section at mid-thickness of the fatigue specimen in the $(x, y)$ plane, as for the nanoindentation tests. The observed section was prepared with a cross section polisher, to preserve the microstructure and avoid polishing artefacts. For the measurements, the sample was tilted to $70^{\circ}$ relative to the incident beam, as in conventional ESBD analysis, and a voltage of $20 \mathrm{kV}$ was used. An area of $600 \times 200 \mu \mathrm{m}$ in the hole edge area was scanned with a step size of $0.5 \mu \mathrm{m}$.
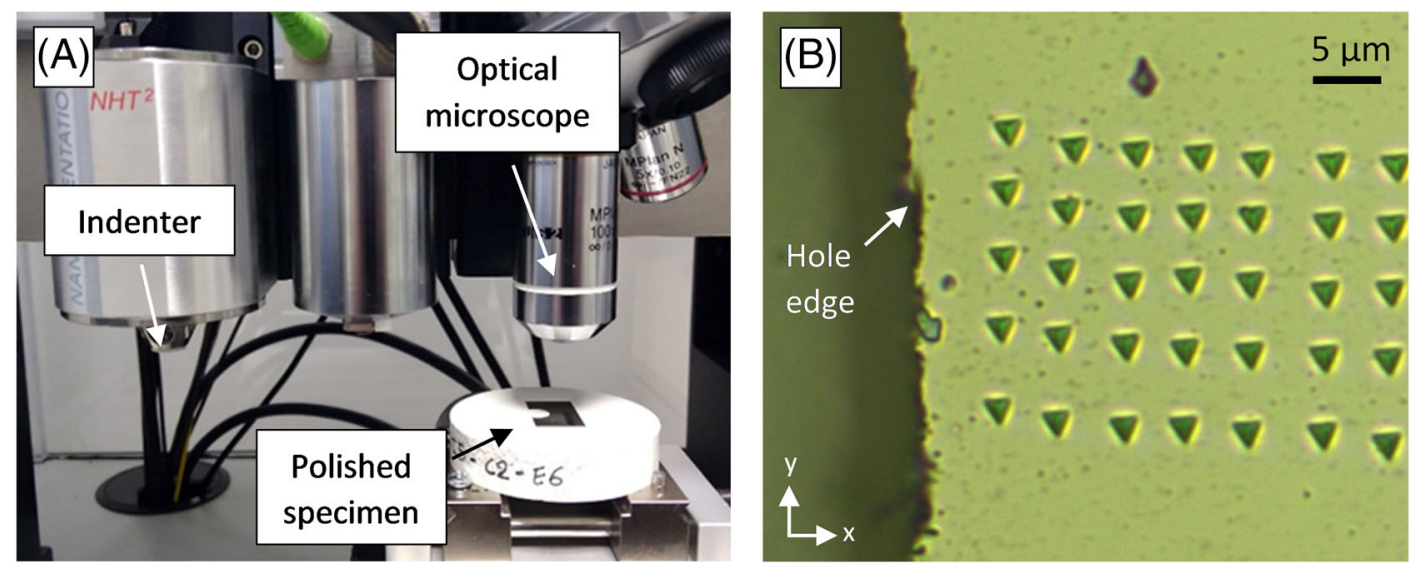

FI G URE 5 Nanoindentation test set-up (A) and example of a nanoindentation matrix (B) 


\subsubsection{Residual stress analysis}

Current techniques for residual stress evaluation (X-ray diffraction and incremental hole drilling) were first considered for the study of the residual stress state of the part. However, these techniques were difficult to implement due to the cylindrical shape of the hole, the large grain size of the material, and the thinness of the material layer affected by residual stresses in the hole edge area.

Therefore, a novel strategy, the Hole Opening Comparative Technique (HOCT), which is suitable for the analysis of residual stresses for thin material layer affected in the hole subsurface, was set up. This method is based on the splitting method ${ }^{28}$ which is usually used to assess the residual stresses in thin-walled tubes. ${ }^{29}$ The HOCT consists in introducing a slot along the half of the working section of the fatigue specimen that opened the hole and measuring the specimen deformation induced by this material removal which indicates the level and sign of residual stresses (Figure 6A). The specimen deformation level indicates the residual stress level: the greater the residual stress state in the hole edge area, the greater the specimen deformation after the opening of the hole. The shape of the deformation profile indicates the residual stress sign: a convex profile corresponds to tensile residual stresses, whereas a concave profile corresponds to compressive residual stresses (Figure 6B).

Thus, the HOCT allows to evaluated the residual stress state in the hole edge area in drilled open-hole T-type specimen in a qualitative way and can be used as a quick comparative test. Moreover, the quantitative analysis of the residual stresses could also be possible through the development of a numerical model which could determine, using the inverse method, the residual stress state corresponding to the specimen deformation induced by the HOCT.

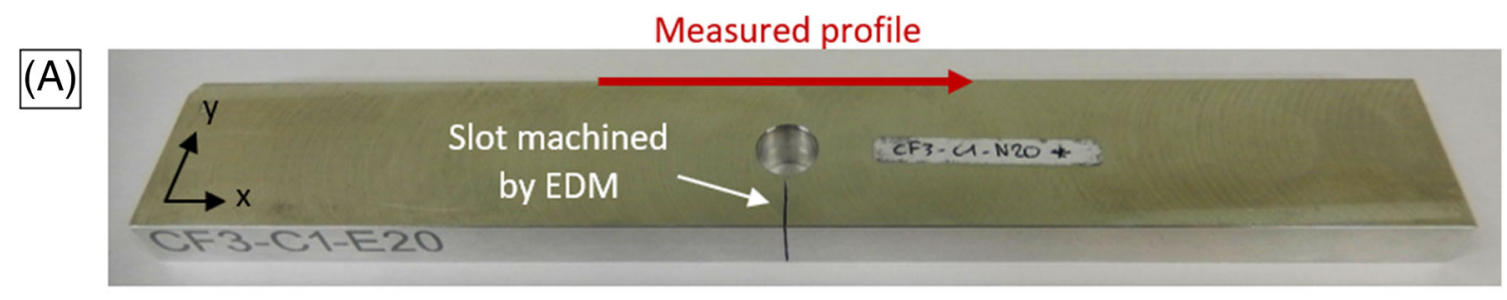

(B)
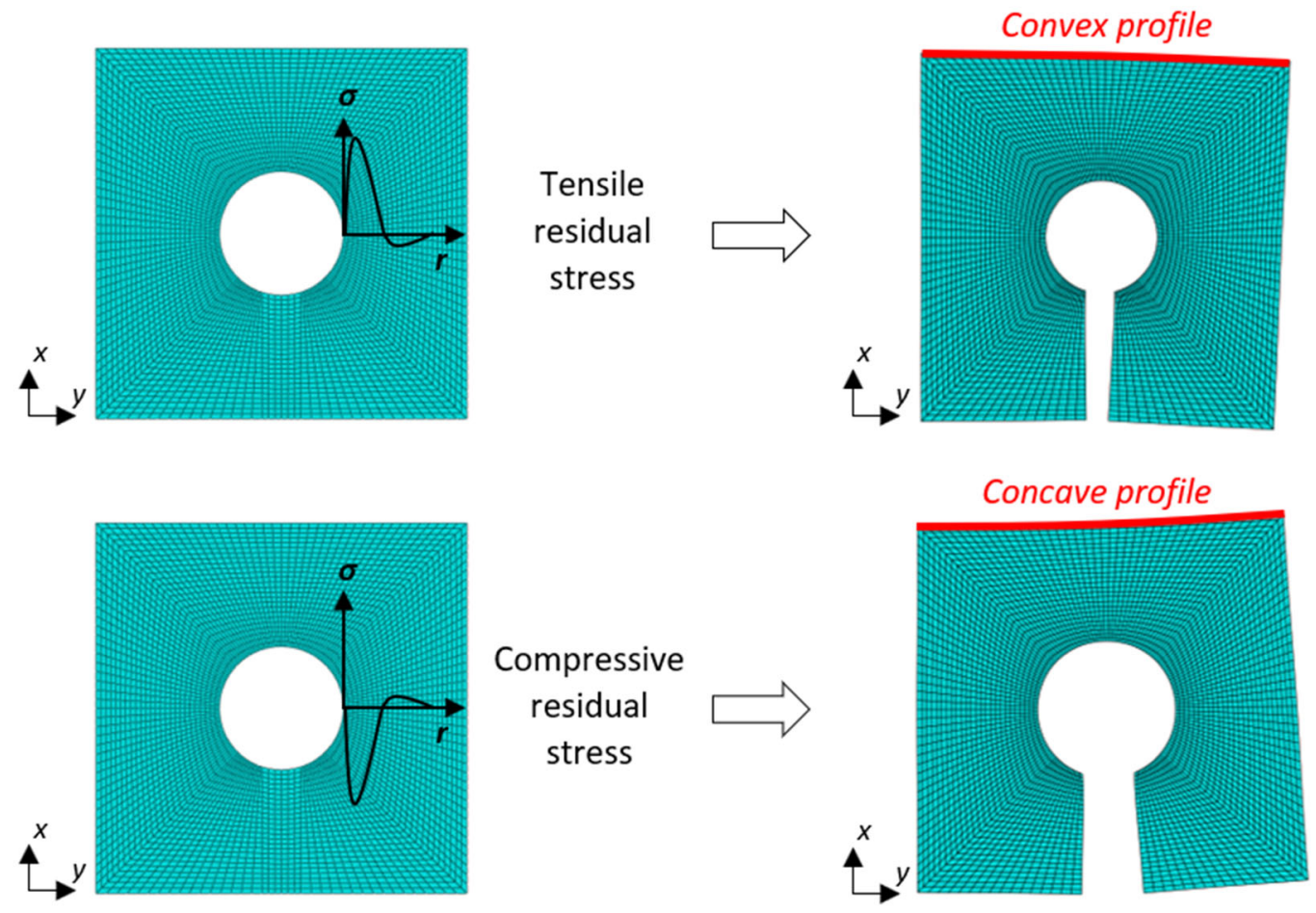

F I G URE 6 Specimen for the residual stress analysis with the HOCT (A) and shape of the deformation profile according to the residual stress sign (B) 
The different steps of the HOCT are given below:

1. Drilling of a hole in a specimen assumed to be free of residual stresses;

2. Measurement of the profile of the specimen after drilling;

3. Machining of the slot by Electrical Discharge Machining (EDM);

4. Measurement of the profile of the specimen after machining of the slot;

5. Analysis of the residual stress state of the specimen through the measured specimen deformation.

In this work, the material studied is the aluminum alloy 2024-T351. With the treatment T351, the material is stretched a controlled amount for stress relief after being solution heat treated. Therefore, in this study, the fatigue specimens can be assumed to be free of residual stress before the drilling operation. Besides, with the HOCT, the machining of the slot is done by EDM which avoids introducing significant levels of residual stress in the specimen. Thus, the specimen deformation measured is

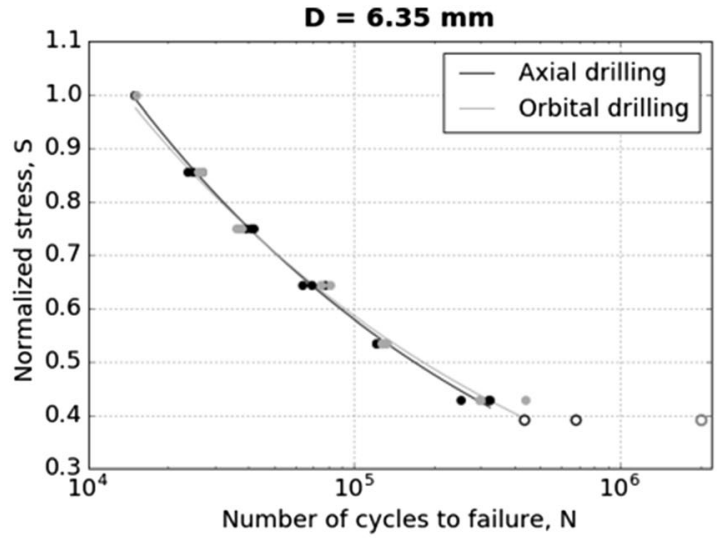

(A)

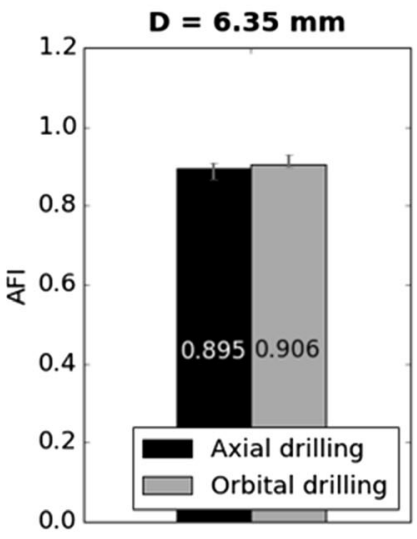

(C) assumed to be essentially related to the residual stresses introduced during the drilling operation.

In the HOCT procedure, the specimen deformation is evaluated through the measurement of a profile shape before and after the material removal. As the residual stresses are assumed to be much greater in the radial and orthoradial directions than in the axial direction, the specimen deformation induced by the HOCT is measured in the $(x, y)$ plane. The measured profile is oriented along the longitudinal direction of the specimen and located at mid-thickness of the specimen on the side opposite the machined slot (Figure 6A). In this study, the profile measurements were performed with an ALICONA Infinite Focus device.

\section{RESULTS}

\subsection{Fatigue life}

For reasons of confidentiality, fatigue test results are presented in Figure 7A,B as semi-log $S-N$ curves

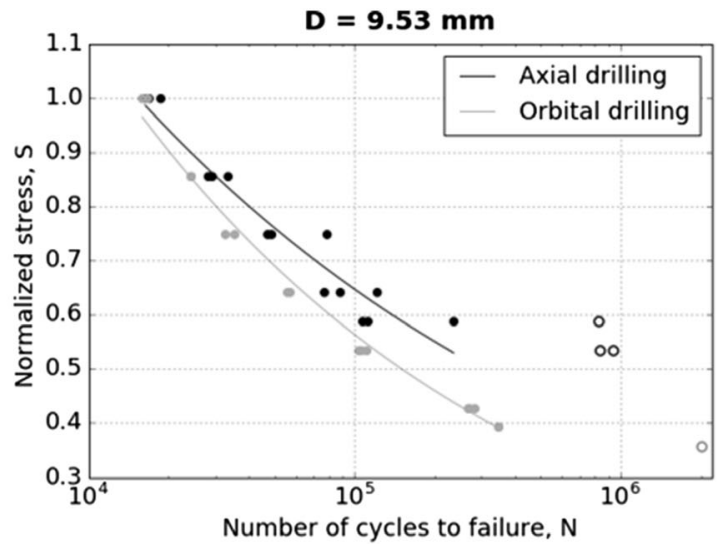

(B)

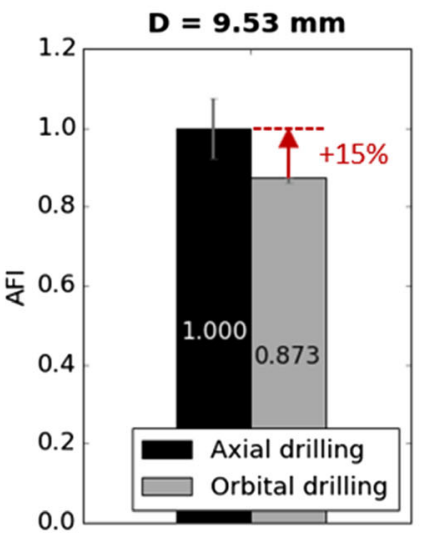

(D)

F I G U RE 7 Wöhler curves obtained for $D=6.35 \mathrm{~mm}(\mathrm{~A})$ and $D=9.53 \mathrm{~mm}$ (B) and corresponding AFI results (C,D) 
(Wöhler curves), with $S$ corresponding to the normalized stress in the working section of the specimen and $N$ corresponding to the number of cycles leading to failure. Power trend curves are plotted on these graphs. In the same way, the values of the surface integrity parameters presented in the following sections (roughness, microhardness, and nanohardness) are also normalized by their maximum value.

$S-N$ curves obtained for $D=6.35 \mathrm{~mm}$ show no difference in fatigue strength between the two drilling processes. In contrast, $S$ - $N$ curves obtained for $D=9.53 \mathrm{~mm}$ show a significant increase in fatigue life for the specimens drilled by the axial technique. This gain in fatigue life can be observed for all stress levels but is greater for the lower ones.

In the aircraft industry, the fatigue performance of a structure is commonly evaluated by the Airbus Fatigue Index (AFI), which corresponds to the stress $S$ associated with a forecast fatigue life of 100,000 cycles. Thus, AFI values were determined for all configurations from $S-N$ curves. They are shown in Figure 7C,D (as values normalized by the maximum AFI value obtained).

For $D=6.35 \mathrm{~mm}$, similar AFI values can be observed for both drilling processes, whereas for $D=9.53 \mathrm{~mm}$, a gain in AFI of $15 \%$ is visible with the axial drilling process.

The fracture surfaces were observed for all drilling configurations. No difference in failure mode was noted between the different configurations. For all specimens, the crack initiated in the hole edge area and the fracture surface was divided into two distinct zones: the crack propagation zone and the final fracture zone (Figure 8).

Thus, the drilling configuration can have a significant influence on the fatigue strength of the drilled part, but it has no impact on the failure mode of the specimen. The differences in fatigue life observed between the drilling configurations were probably related to differences in the hole surface integrity. Characterization test results of the hole surface integrity are presented in the following sections.

\subsection{Roughness measurements}

Among all the roughness parameters measured, only the results of arithmetic average height of profile ( $\mathrm{Ra})$, which gives an average indication of the overall surface topological state, are presented here. They are shown in Figure 9.

For all drilling configurations, the measured $\mathrm{Ra}$ value complies with the aeronautical specification. No correlation can be established between the Ra results and the fatigue test results. A significant difference in $\mathrm{Ra}$ is observed between the two drilling processes for $D=6.35 \mathrm{~mm}$ whereas no difference in fatigue life is noticed between the two drilling techniques for this hole diameter. This is probably related to the relatively low $\mathrm{Ra}$ values measured compared to the aeronautical specification. The Ra values are not high enough to have an impact on the fatigue strength of the part.

The possible relationship between the hole roughness and the fatigue life results was also studied for all the other $2 \mathrm{D}$ and $3 \mathrm{D}$ roughness parameters measured. No obvious correlation between the roughness parameters and the fatigue strength of the drilled part can be highlighted from this analysis. As for Ra, this is explained by the low measured values of the $2 \mathrm{D}$ and $3 \mathrm{D}$ roughness parameters which do not indicate a degraded surface texture. In this study, the drilled hole surfaces seem to have a fatigue behavior corresponding to the first domain of the Kitagawa diagram. ${ }^{30}$ This domain, which is associated to small defect sizes, corresponds to a negligible influence of the defect size on the fatigue strength and to

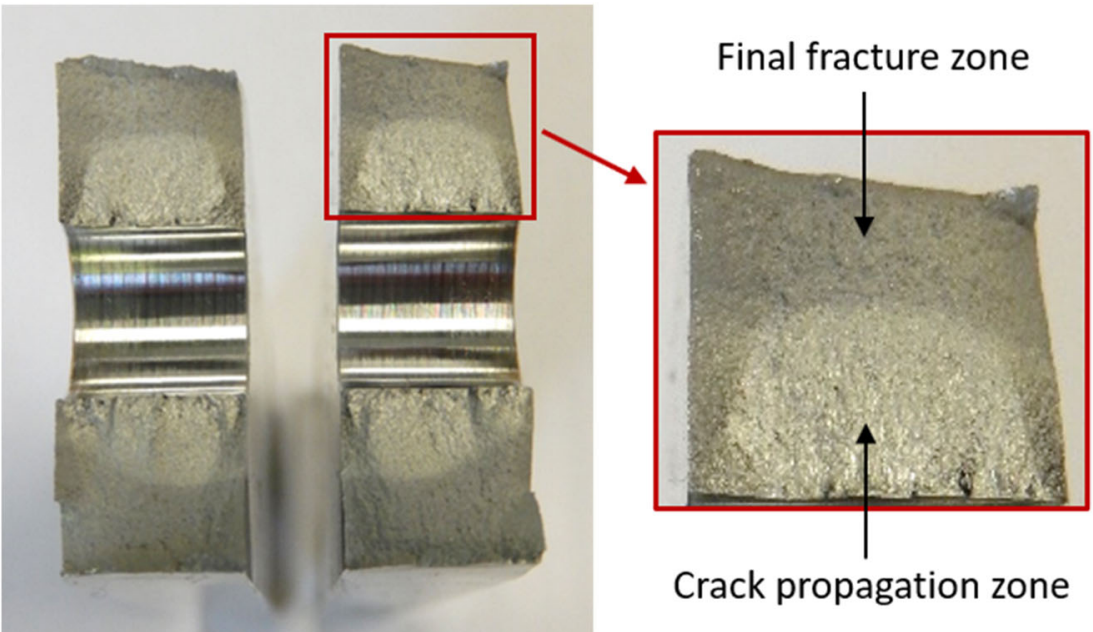

F I G URE 8 Example of a fracture surface 
a crack initiation controlled by the microstructural state of the material.

Thus, in this study, the hole roughness is not a major factor influencing the fatigue life of the drilled part. That is why the further characterization of the hole surface integrity focuses on the internal aspects of surface integrity.

\subsection{Hardness measurements}

After analysis of the topographic aspects of the hole surface integrity, the metallurgical and mechanical aspects were investigated. The Vickers microhardness measurements carried out in this framework are presented in Figure 10.

For $D=6.35 \mathrm{~mm}$, holes obtained by axial and orbital drilling processes have similar microhardness levels, whereas for $D=9.53 \mathrm{~mm}$, a significant difference in microhardness level is observed between the two drilling techniques. For this diameter, a gain of $29 \%$ in microhardness level can be seen for axial drilling.

These results show a correlation of fatigue life results with microhardness measurements: the increase in hole microhardness for axial drilling at $D=9.53 \mathrm{~mm}$ seems to explain the gain in fatigue life observed for the same configuration (Figure 7).
FI G U RE 9 Roughness average results for $D=6.35 \mathrm{~mm}(\mathrm{~A})$ and $D=9.53 \mathrm{~mm}(\mathrm{~B})$

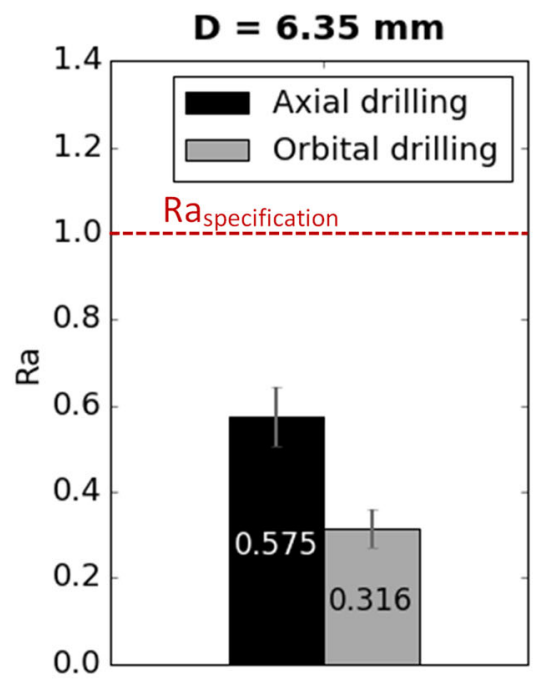

(A)

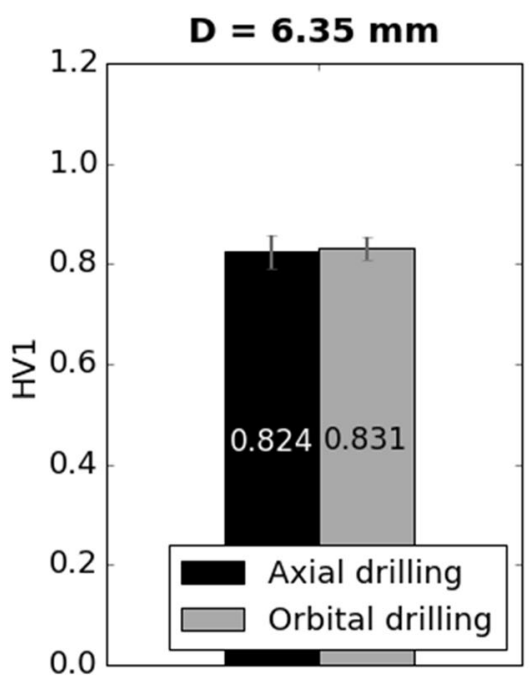

(A)

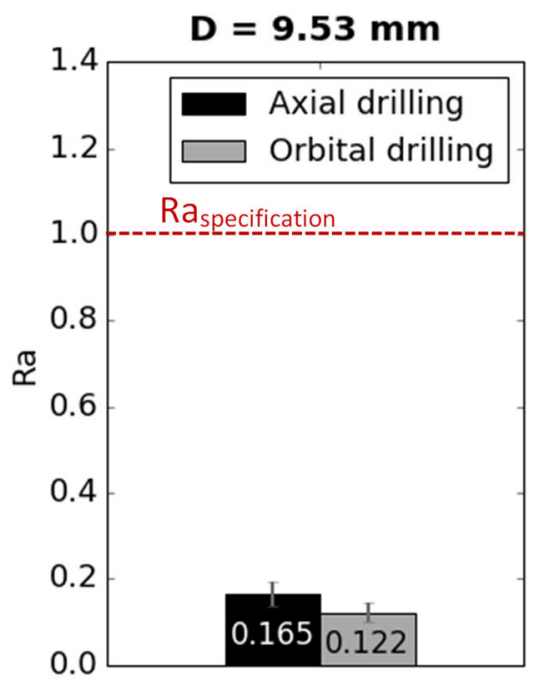

(B)

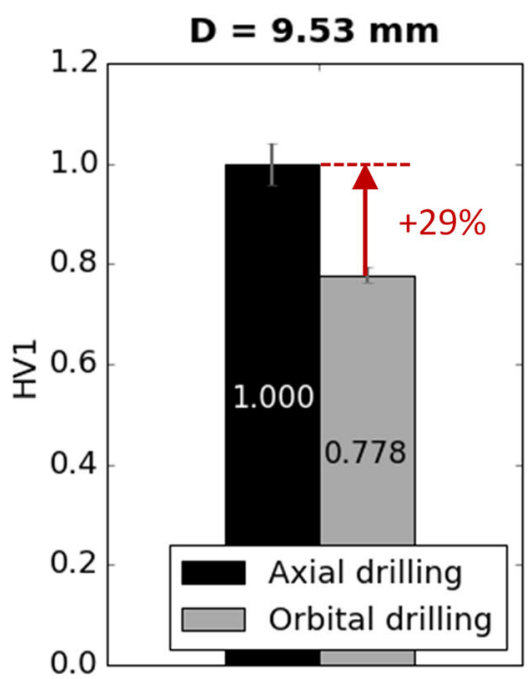

(B)
FI G U RE 10 Vickers microhardness results for $D=6.35 \mathrm{~mm}$ (A) and $D=9.53 \mathrm{~mm}$ (B) 
To study this result further, nanoindentation tests were performed. The test results are presented in Figure 11 as graphs showing the variation of the nanohardness according to the distance from the hole edge.

For $D=6.35 \mathrm{~mm}$, nanohardness results show a similar material depth affected by hardness variation, around $15 \mu \mathrm{m}$ for both drilling processes. In contrast, for $D=9.53 \mathrm{~mm}$, a significant difference in material depth affected is observed between the two drilling techniques. The material depth affected for orbital drilling seems to be very small (less than $5 \mu \mathrm{m}$ ), whereas it is around $40 \mu \mathrm{m}$ for axial drilling. Also, during indentation tests for the specimen corresponding to axial drilling at $D=9.53 \mathrm{~mm}$, the first indents column induced quite small, irregular prints from which no hardness value could be calculated. This indicates that the nanohardness value of the hole subsurface obtained for this configuration seems to be high.

These results highlight the thinness of the subsurface material layer affected by the drilling operation of a 2024-T351 aluminum part, in agreement with the numerical model. The nanohardness results are in accordance with the microhardness results. The hole hardness seems to be a major factor influencing the fatigue behavior of a drilled part with a positive influence.

\subsection{SEM-EBSD analysis}

In order to identify the phenomena responsible for the difference in hole surface hardness, a metallographic analysis was carried out. In this framework, GROD maps of the hole edge area obtained through SEM-EBSD analysis (Figure 12) were analyzed.

The GROD map obtained for axial drilling at $D=9.53 \mathrm{~mm}$ shows a significant material depth affected by grain misorientations, around $40 \mu \mathrm{m}$ depth. This affected material layer varies slightly according to the grains. In contrast, almost no grain misorientation, or only some a few microns deep, is observed for the other drilling configurations. A material layer affected by grain misorientation corresponds to a strain hardened material layer. This means that axial drilling at $D=9.53 \mathrm{~mm}$ induces a significant strain hardening of the hole subsurface compared to other drilling configurations.

These results explain the microhardness and nanohardness results. The increase in hardness in the

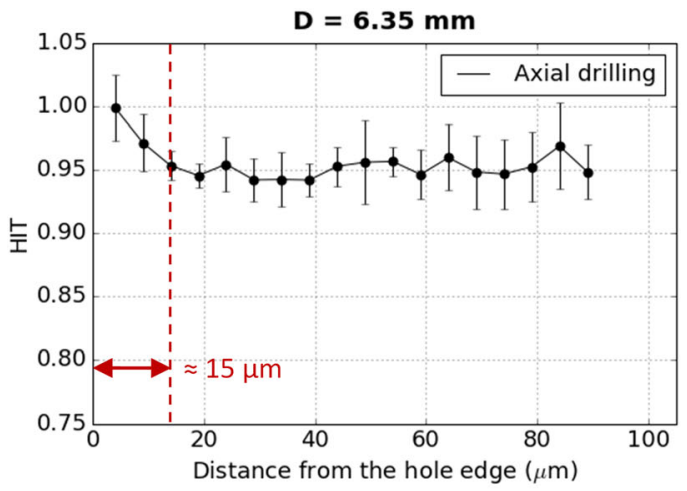

(A)

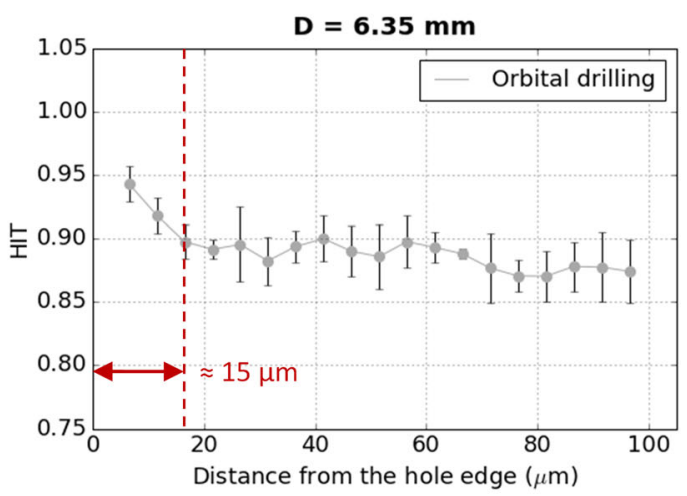

(C)

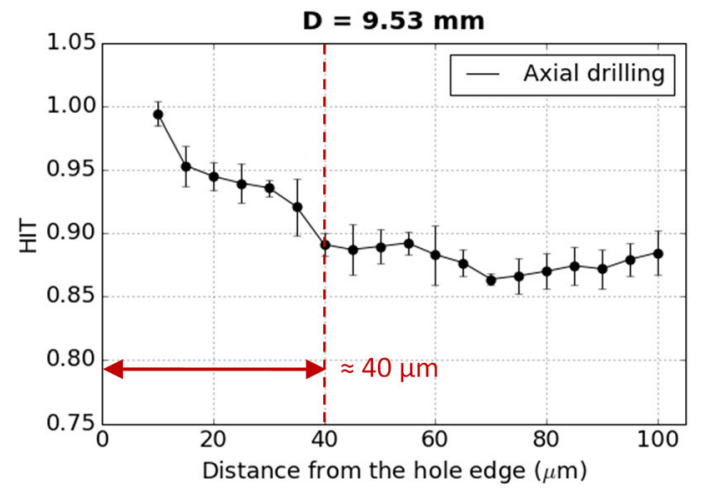

(B)

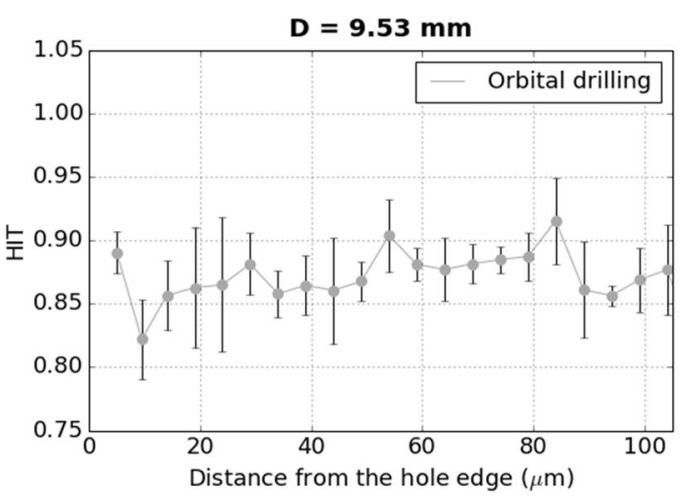

(D)

F I G URE 11 Nanohardness results for $D=6.35 \mathrm{~mm}(\mathrm{~A}, \mathrm{C})$ and for $D=9.53 \mathrm{~mm}(\mathrm{~B}, \mathrm{D})$ 
hole surface and subsurface, for axial drilling at $D=9.53 \mathrm{~mm}$, seems to be due to the significant strain hardening of the material in the hole edge area. This assumption is strengthened by the fact that the affected material depths identified with the nanoindentation tests and with the SEM-EBSD tests are the same.

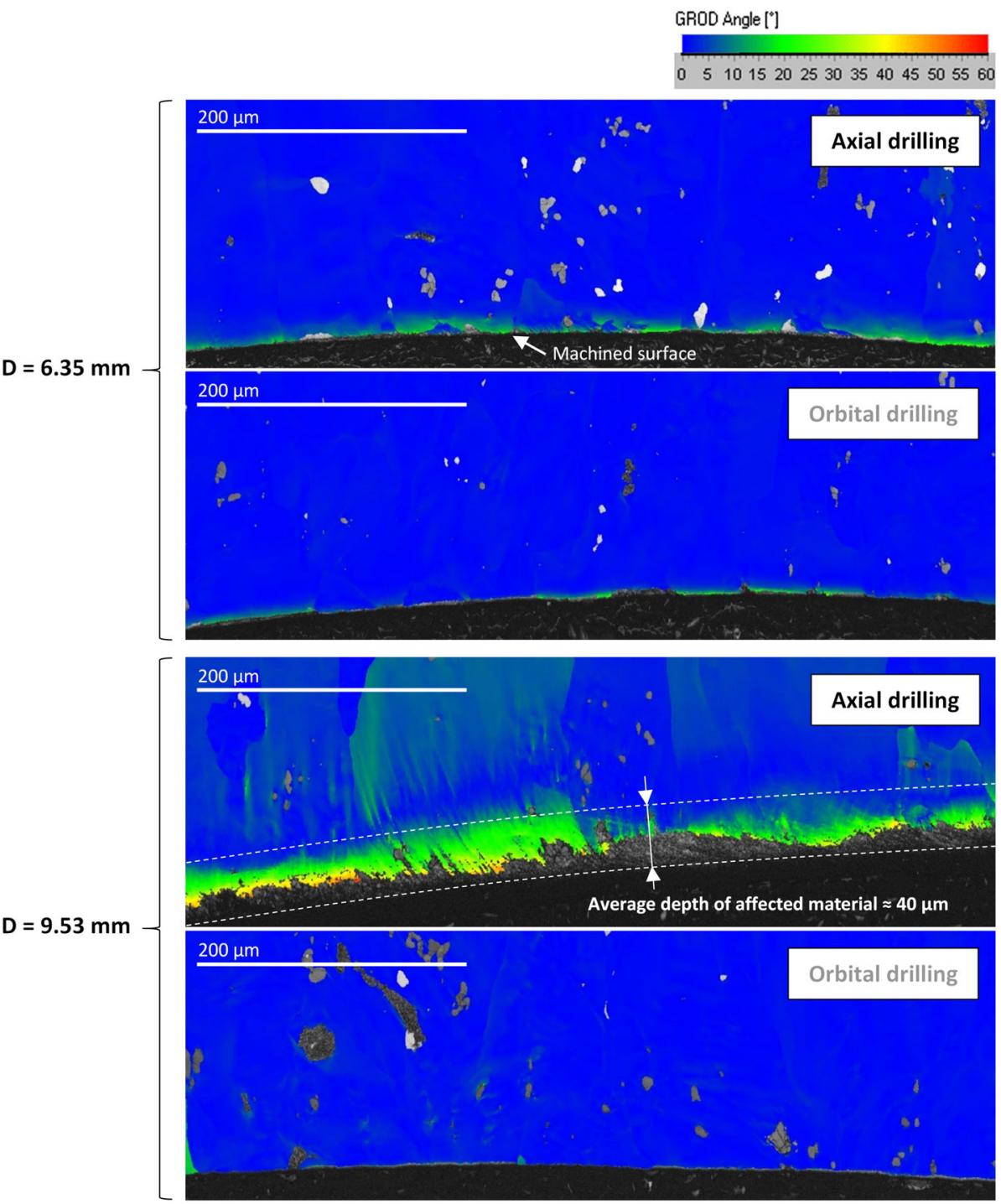

FIG URE 12 GROD maps obtained with the SEM-EBSD analysis

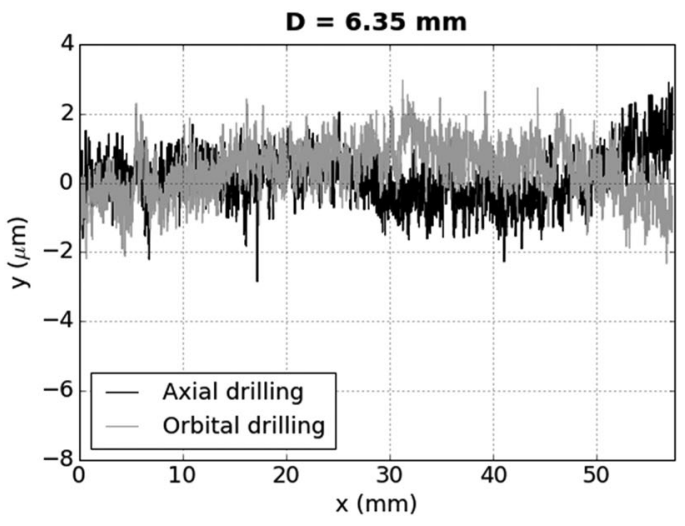

(A)

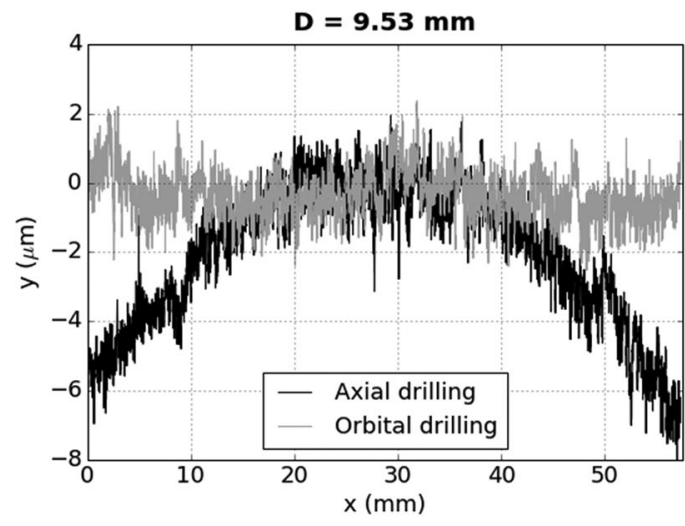

(B)

FIG URE 13 Specimen deformation obtained with the HOCT for $D=6.35 \mathrm{~mm}(\mathrm{~A})$ and $D=9.53 \mathrm{~mm}(\mathrm{~B})$ 


\subsection{Residual stress analysis}

The residual stress state of the drilled part, which, according to the literature, can also have a significant impact on the fatigue life, ${ }^{31,32}$ was investigated through the novel HOCT technique. Specimen deformations obtained with HOCT are presented in Figure 13.

No deformation of the specimen is noticed after the material removal for the case of axial and orbital drilling at $D=6.35 \mathrm{~mm}$ and the case of orbital drilling at $D=9.53 \mathrm{~mm}$. However, significant specimen deformation is observed for axial drilling at $D=9.53 \mathrm{~mm}$. This means that this drilling configuration induces significant residual stress fields in the hole edge area compared to the others.

These results show a correlation of the fatigue test results with the residual stress state of the material. A high fatigue quality index is associated with the presence of significant residual stresses in the hole edge area. Furthermore, a high residual stress state is associated with high hole hardness.

\section{DISCUSSION}

This study focuses on drilling processes corresponding to industrial applications, that is to say, using optimum tools and cutting parameters in order to obtain high surface quality in accordance with the industrial specification. For this study case, the hole roughness is not a major factor influencing the fatigue life of the drilled part. In accordance with Siebel and Gaier ${ }^{18}$ it seems that, below a given limit, which could be the aircraft specification here, the hole roughness does not significantly impact the fatigue behavior. However, if the roughness reaches high values, its influence could be significant. This confirms the importance of the roughness specification for these aluminum alloys.

In contrast, the hole hardness has a significant positive influence on the fatigue life of the drilled part in this study. A variation in hardness can be related to several factors. It can be related to mechanical loading inducing the strain hardening of the hole subsurface and to thermal loading inducing material transformations, and for nanohardness, it can also be related to the residual stresses induced by thermomechanical loading. Regarding the impact of the thermal loading, the temperatures reached during an aluminum drilling operation do not seem to be high enough to induce a phase transformation. ${ }^{1}$ Besides, an SEM analysis of the precipitation state of the hole subsurface, conducted as part of the study, showed no increase in the number or size of the precipitates, which could reflect precipitation hardening, for the case of axial drilling at $D=9.53 \mathrm{~mm}$. Thus, it seems that the thermal loading involved during drilling of a 2024-T351 aluminum part has no significant influence on the hole surface integrity. Regarding the impact of the mechanical loading, the SEM-EBSD analysis showed a significant material depth affected by strain hardening for the axial drilling process at $D=9.53 \mathrm{~mm}$. Thus, it seems that, in our study case, the mechanical loading involved in drilling controls the hole surface integrity.

Therefore, the increase in hole hardness for the aluminum alloy studied is essentially related to the strain hardening of the hole subsurface, which is induced by the severe mechanical loading applied on the machined surface during the drilling process. The positive influence of the hole hardness on the fatigue life can then be explained by the increase in yield strength in the hole edge induced by the strain hardening, which slows damage generation (crack initiation) in this area.

HOCT results showed that a significant hole hardness induced by strain hardening is associated with a significant residual stress state of the part. Severe mechanical loading applied to the machined surface simultaneously generates high plastic strain and high residual stresses. The residual stresses can remain in the part because of the strain hardened material layer. Thus, it seems difficult to dissociate these two aspects. In order to study the impact of the residual stress on the fatigue strength in greater depth, it would be interesting to develop a numerical model capable of using the inverse method to determine the residual stress state corresponding to the fatigue specimen deformation obtained with the HOCT.

For the aircraft industry, it would be interesting to identify a surface integrity characteristic that would be quite easy to evaluate, as an indicator of the fatigue strength, in order to be able to assess the fatigue life of aircraft structures easily. The correlation between the hole surface microhardness and the fatigue strength of the drilled part has been demonstrated in this study, and the measurement of this surface integrity characteristic seems relatively accessible: it does not require surface preparation, the test time is short, and the cost of the device is moderate. Thus, the Vickers microhardness could be identified as an indicator of the fatigue strength for aluminum 2024-T351 drilled parts.

\section{CONCLUSIONS}

In order to identify the surface integrity parameters that control the fatigue strength of a 2024-T351 aluminum drilled part, fatigue tests were carried out on open-hole specimens and the surface integrity of the holes was characterized with a study scale and techniques suitable for 
aluminum drilled surfaces. An innovative technique for the residual stress evaluation of aluminum drilled parts, the HOCT, was implemented. The main conclusions of the study are as follows:

- For hole roughness levels obtained with industrial drilling processes, the hole roughness has no significant influence on the fatigue strength.

- The hole hardness has a significant positive influence on the fatigue life and could be identified as a fatigue strength indicator for 2024-T351 aluminum aircraft drilled parts.

- The increase in hole hardness for a 2024-T351 aluminum drilled part is mainly due to the strain hardening of the subsurface material, induced by severe mechanical loading during the machining process.

- A high hole hardness is associated with a significant residual stress state of the part in the hole edge area.

The study focused on the fatigue life of open-hole specimens as a first step, in order to avoid the phenomena associated with the introduction of a fastener (impact of the tightening torque, impact of the assembly clearance or interference level, etc.). In future works, it would be interesting to study the fatigue life of assemblies of drilled parts with fasteners, to assess the influence of the hole surface integrity in this case.

Finally, in order to be able to improve the fatigue life of aircraft structures, the influence of the drilling process (tool geometry, cutting parameters, associated thermomechanical loading) will have to be studied in more detail in order to develop a drilling process generating optimum hole surface integrity.

\section{AUTHOR CONTRIBUTIONS}

Development of the original idea and the protocol: Alexandra Lacombe, Yann Landon, and Manuel Paredes. Analysis and interpretation of data: Alexandra Lacombe, Yann Landon, Manuel Paredes, and Damien Texier. Writing original draft: Alexandra Lacombe. Writing, review and editing: Alexandra Lacombe, Yann Landon, Manuel Paredes, Clément Chirol, and Audrey Benaben.

\section{ACKNOWLEDGMENT}

The authors would like to thank Airbus France for its financial and technical support.

\section{DATA AVAILABILITY STATEMENT}

Research data are not shared.

\section{NOMENCLATURE}

$A \quad$ ultimate elongation

D nominal hole diameter

$\begin{array}{ll}D_{\text {tool }} & \begin{array}{l}\text { tool diameter } \\ f_{\mathrm{a}}\end{array} \\ \text { HIT } & \begin{array}{l}\text { axial feed per tool rotation } \\ \text { nanohardness calculated using the Oliver and }\end{array} \\ \text { HV1 } & \begin{array}{l}\text { Pharr method } \\ \text { Vickers microhardness measured with an }\end{array} \\ N_{\mathrm{orb}} & \begin{array}{l}\text { orbital rotation speed } \\ N_{\mathrm{spindle}}\end{array} \\ r & \text { spindle rotation speed } \\ R_{\mathrm{a}} & \text { tool edge radius } \\ R_{\mathrm{m}} & \text { arithmetic average height of a profile } \\ R_{\mathrm{p} 0.2} & \text { yield strength } \\ R_{\mathrm{q}} & \text { root mean square height of a profile } \\ R_{\mathrm{z}} & \text { mean peak to valley height of a profile } \\ S_{\mathrm{a}} & \text { arithmetic average height of a surface } \\ S_{\mathrm{dq}} & \text { root mean square gradient of a surface } \\ S_{\mathrm{ku}} & \text { kurtosis of a surface } \\ S_{\mathrm{p}} & \text { maximum peak height of a surface } \\ S_{\mathrm{q}} & \text { root mean square height of a surface } \\ S_{\mathrm{sk}} & \text { skewness of a surface } \\ S_{\mathrm{v}} & \text { minimum valley depth of a surface } \\ S_{\mathrm{z}} & \text { maximum height of a surface } \\ V_{\mathrm{c}} & \text { cutting speed } \\ V_{\mathrm{fa}} & \text { axial feed rate }\end{array}$

\section{ORCID}

Alexandra Lacombe (D) https://orcid.org/0000-0003-27154213

Damien Texier (1) https://orcid.org/0000-0002-4473-7827

\section{REFERENCES}

1. Girot F, Cahuc O, Couetard Y, K'Nevez JY, Laporte S, Darnis P et al. Perçage des structures aéronautiques: Les résultats du projet MEDOC. 1er colloque Aquitaine - Québec - Mécanique des Matériaux et des Structures pour l'Aéronautique, 2008.

2. Elajrami M, Benguediab M, Ronald G. Effect of various drilling procedures on the fatigue life of rivet holes. Synthèse: Revue des Sciences et de la Technologie. 2008;19:67-75.

3. Ralph WC, Johnson WS, Makeev A, Newman JC. Fatigue performance of production-quality aircraft fastener holes. Int $J$ Fatigue. 2007;29(7):1319-1327.

4. Everett RA. The effect of hole quality on the fatigue life of 2024-T3 aluminum alloy sheet. NASA/TM-2004-212658, ARL-TR-3106, 2004.

5. Ralph WC, Johnson WS, Toivonen P, Makeev A, Newmanjr J. Effect of various aircraft production drilling procedures on hole quality. Int J Fatigue. 2006;28(8):943-950.

6. Field M, Kahles JF. Surface integrity of machined and ground high strength steels. DMIC Rep. 1964;210:54-77.

7. Mondelin A. Modélisation de l'intégrité des surfaces usinées: Application au cas du tournage finition de l'acier inoxydable 15-5PH. PhD Thesis. 2012.

8. Novovic D, Dewes RC, Aspinwall DK, Voice W, Bowen P. The effect of machined topography and integrity on fatigue life. Int J Mach Tool Manuf. 2004;44(2):125-134. 
9. M'Saoubi R, Outeiro JC, Chandrasekaran H, Dillon OW Jr, Jawahir IS. A review of surface integrity in machining and its impact on functional performance and life of machined products. Int J Sustain Manuf. 2008;1(1-2):203-236.

10. Pramanik A, Dixit AR, Chattopadhyaya $S$, et al. Fatigue life of machined components. Adv Manuf. 2017;5(1):59-76.

11. Suraratchai M, Limido J, Mabru C, Chieragatti R. Modelling the influence of machined surface roughness on the fatigue life of aluminium alloy. Int J Fatigue. 2008;30(12):2119-2126.

12. Maximov JT, Anchev AP, Dunchev VP, Ganev N, Duncheva GV, Selimov KF. Effect of slide burnishing basic parameters on fatigue performance of 2024-T3 high-strength aluminium alloy. Fatigue Fract Eng Mater Struct. 2017;40(11): 1893-1904.

13. Wang $\mathrm{Y}$, Zhu $\mathrm{Y}$, Hou S, Sun $\mathrm{H}$, Zhou $\mathrm{Y}$. Investigation on fatigue performance of cold expansion holes of 6061-T6 aluminum alloy. Int. J. Fatigue. 2017;95:216-228.

14. Cuellar SD, Hill MR, DeWald AT, Rankin JE. Residual stress and fatigue life in laser shock peened open hole samples. Int. J. Fatigue. 2012;44:8-13.

15. Sasahara H, Kawasaki M, Tsutsumi M. The effect on fatigue life of residual stress and surface hardness resulting from different cutting conditions of $0.45 \% \mathrm{C}$ steel. Int J Mach Tool Manuf. 2005;45(2):131-136.

16. Yao C, Ma L, Du Y, Ren J, Zhang D. Surface integrity and fatigue behavior in shot-peening for high-speed milled 7055 aluminum alloy. Proc Inst Mech Eng Part B J Eng Manuf. 2017; 231(2):243-256.

17. Wagner L, Gregory JK. Thermomechanical surface treatment of titanium alloys. Mater Sci Forum. 1994;163-165:159-172.

18. Siebel E, Gaier M. Influence of surface roughness on the fatigue strength of steels and non-ferrous alloys. Eng Dig. 1957; 18:109-112.Translation from VDI Zeitschrift, 1956;98(30): $1715-1723$

19. Koster W. Effect of residual stress on fatigue of structural alloys. Proc Third Int Conf ASM Int. 1991;1-9.

20. Atlati S. Développement d'une nouvelle approche hybride pour la modélisation des échanges thermiques à l'interface outilcopeau. PhD Thesis. 2012.

21. Sun D, Lemoine P, Keys D, et al. Hole-making processes and their impacts on the microstructure and fatigue response of aircraft alloys. Int J Adv Manuf Technol. 2018;94(5-8):1719-1726.

22. Deitert L. Orbital drilling. Aerospace Technology Conference and Exposition 2011
23. Pereira RBD, Brandão LC, De Paiva AP, Ferreira JR, Davim JP. A review of helical milling process. Int J Mach Tool Manuf. 2017;120:27-48.

24. Faurie JP, Monnier P, Niku-Lari A, Sutterlin R. Guide du dessinateur Les concentrations de contraintes. Publications CETIM; 2003.

25. Pharr GM. Measurement of mechanical properties by ultra-low load indentation. Mater Sci Eng a. 1998;253(1):151-159.

26. Kamaya M, Wilkinson AJ, Titchmarsh JM. Measurement of plastic strain of polycrystalline material by electron backscatter diffraction. Nucl Eng Des. 2005;235(6):713-725.

27. Lehockey EM, Lin YP, Lepik OE. Mapping residual plastic strain in materials using electron backscatter diffraction. Electron Backscatter Diffraction in Materials Science. 2000; 247-264.

28. Walton HW. Deflection methods to estimate residual stress. In: G. Totten et al. (Éds.), Handbook of Residual Stress and Deformation of Steel. 2002:89-98, ASM International.

29. Baldwin WM. Residual stresses in metals. Proc American Society for Testing and Materials 1949:49

30. Kitagawa HTS. Applicability of fracture mechanics to very small cracks or the cracks in the early stage. Proceedings of the Second International Conference on Mechanical Behaviour of Materials. 1976;627-631.

31. de Castro PMST, de Matos PFP, Moreira PMGP, da Silva LFM. An overview on fatigue analysis of aeronautical structural details: open hole, single rivet lap-joint, and lap-joint panel. Mater Sci Eng a. 2007;468-470:144-157.

32. Sticchi M, Schnubel D, Kashaev N, Huber N. Review of residual stress modification techniques for extending the fatigue life of metallic aircraft components. Appl Mech Rev. 2015;67(1): 010801-1-010801-9. 